https://www.journal-imab-bg.org

Original article

\title{
PROBLEMS AND PERSPECTIVES FOR THE LABOUR MARKET IN HEALTH CARE BULGARIA AS A PART OF THE EUROPEAN UNION AND THE COMMUNITY POLICIES
}

\author{
Neli Gradinarova ${ }^{1}$, Evgeni Ivanov², \\ 1) Department of Medical Ethics and Law, Faculty of Public Health, Medical \\ University - Sofia, Bulgaria \\ 2) Department of Medical Pedagogy, Faculty of Public Health, Medical \\ University-Sofia, Bulgaria
}

\begin{abstract}
:
Specialists working in health care are the main ssets which each EU member state has. There are many tasks and challenges for the health systems in the Union. The demand for health services in the Community is increasing, and concurrently there are certain restrictions in the offering of such services. National policies and healthcare authorities in all EU member states need to consider current issues of the Community and adapt their healthcare systems according to the lack of a sufficient number of health specialists and the ageing population.

On 1 March 2005, Bulgaria signed the EU accession treaty, and since 1 January 2007, the country is a member of the Community. As such, it must follow European sources of law and conduct a harmonized policy of governance along with the rest of the member states.

In 2008 the EU accepted a Green Book on workers in health care in Europe [1]. The demand for health services in the Community is increasing, and concurrently there are certain restrictions in the offering of such services.

In order to verify and analyse the attitude for training and career development of students in nursing care, a survey was conducted among first year students in nursing care from the Faculty of Public Health, Medical University - Sofia. The average age of the first year students is 30, and the results show a need for change and attracting younger people into medical majors. $66,04 \%$ of respondents believe that nursing care would be more attractive for future students if their competencies were expanded, while $54 \%$ of the respondents believe that medical majors could be more attractive for future students if mass media and Internet advertising are included to promote such majors.

There are many challenges on a national and Community level. Health is a main value and healthcare is a part of the national security of any country. Ceaseless migration of health professions and the outflow of candidates for the medical specialities in Bulgaria present serious challenges to the country. It is necessary to take adequate measures to solve actual problems in health care and to ensure the labour market with health professionals.
\end{abstract}

Keywords: Market labour, healthcare, EU, Bulgaria, perspectives

\section{INTRODUCTION:}

The labour market is of key importance to the stability and prosperity of the economy of every country as well as for the social and public development of the country. The social and economic basis that influences the labour market is a cumulative result of the proper functioning of many spheres - demography, healthcare, education, the pension system, legal system and business climate. The labour market is one of the priority sectors of the EU.

According to data from the National Statistical Institute in Bulgaria until 31 December 2016, the population of Bulgaria is $7,101,859$, which represents $1,48 \%$ of the population of the European Union. 4,304,436 of them are in employable age, including 2,262,326 men and 2,042,110 women. As at June 2017 in the economic activities of the country: human healthcare and social sector - work 142,781 persons of the total population of the country.

In 2017, it was the 10th anniversary of Bulgaria's accession to the EU. The EU membership of the country turned its citizens into EU citizens, which means that they can use the rights and benefits given to them by the EU.

In June 2010 the European Council adopted the Europe 2020 strategy [2], which is a multi-lateral strategy for growth and jobs for the period 2010-2020 and its aim is to help Europe overcome the heavy economic crisis since the 1930s. The Europe 2020 strategy determines three priorities: intelligent growth: building knowledge-based and innovative economy, sustainable growth: encouraging a more environment-friendly and competitive economy with the more efficient use of resources and inclusive growth: stimulating the economy with levels of employment, which will lead to social and territorial cohesion.

In 2008 the EU accepted a Green Book on workers in health care in Europe. There are many tasks and challenges for the health systems in the Union. The demand for health services in the Community is increasing, and 
concurrently there are certain restrictions in the offering of such services. National policies and healthcare authorities in all EU member states need to consider current issues of the Community and adapt their healthcare systems according to the lack of a sufficient number of health specialists and the ageing population. The implementation of new technologies for diagnostics, prevention and treatment improves the quality of the services provided in the field of healthcare; however, these technologies require financial resources and qualified staff to operate the implemented technologies. In order to meet the needs of the population in the field of healthcare, the health systems need an efficient workforce. In practice, health care is one of the most significant sectors of the EU economy and provides employment to one of every ten employees in the EU and approximately $70 \%$ of the healthcare budgets are allocated for wages and other expenses, which are directly connected with the work activities of the workers in health care.

In 2007 the European Commission published the White Paper: Together for Health [3], which forms the health strategy of the Community. The EU and its member states stand together in front of the common challenges of the Union - diseases, inequality, change in climate, insufficiency of health professionals in the entire community. The purpose of the strategy is to contribute to better lifelong health for the citizens by protecting them from health threats and supporting the introduction of the new technologies in medicine.

With the adopted in 2008 Green book, the EU continues its strategy in the sphere of health care by focusing on issues related to the work force of the EU in the health sector. The aim of the Green Book is to help the national governments deal together with the challenges faced by the workers in health care in the EU - ageing population and ageing work force in the health sector, insufficient young people in the health care, insufficient young specialists in health care, migration of health workers within the EU and outside of it.

Article 152 of the Treaty on the EU [4] says that "Community action in the field of public health shall fully respect the responsibilities of the Member States for the organisation and delivery of health services and medical care". Concurrently the same articles underline that the Community shall encourage cooperation between the Member States and the coordination of their policies and programmes. Community actions aim to complement national policies; however, the main responsibility for organization and provision of health services is borne by the EU Member States. The EU may only provide support to the member states and contribute to the exchange of good practices.

The ageing of the population in Europe goes along with the ageing of the work force. In the period from 1995 and 2000 , the number of medical doctors below the age of 45 in Europe decreased by $20 \%$ and the number of medical doctors at the age over 45 increased by more than $50 \%$. The average values increased also for the nursing staff - in five member states almost half of the nurses are over 45 years old. The crisis with the human resources in health care may be overcome by training, recruitment and retention of young staff in the healthcare sector and retention of trained staff in mature age.

The Council Recommendation of 11 July 2017 on the 2017 National Reform Programme of Bulgaria outlined the following: According to the Council of the EU as at July 2017 [5] the trends on the labour market in Bulgaria are positive, but there are structural issues. The work force in Bulgaria is decreasing due to the ageing of the population combined with emigration. It is of major significance for the country to utilize the unused potential of the work force, the inclusion of young people on the labour market is limited, and there is a deficit of skills and qualified staff. The main challenges in healthcare remain the limited accessibility, the poor financing, emigration of specialists and poor health results.

\section{MATERIALS AND METHODS:}

In order to verify and analyse the attitude for training and career development of students majoring nursing care, a survey was conducted among the first year students in nursing care from the Faculty of Public Health, Medical University - Sofia.

A pilot survey was conducted in the period 20.09.2017-20.10.2017 and included 87 students in nursing care. Students were selected for the survey on a random basis; the survey was anonymous, which gives ground to claim for representativeness of the results.

\section{RESULTS AND DISCUSSION:}

To create a clearer profile of the responding students and to analyse the trend among the studying specialists in health care, they were asked about their age, fig. 1 .

Fig. 1. Age of respondents.

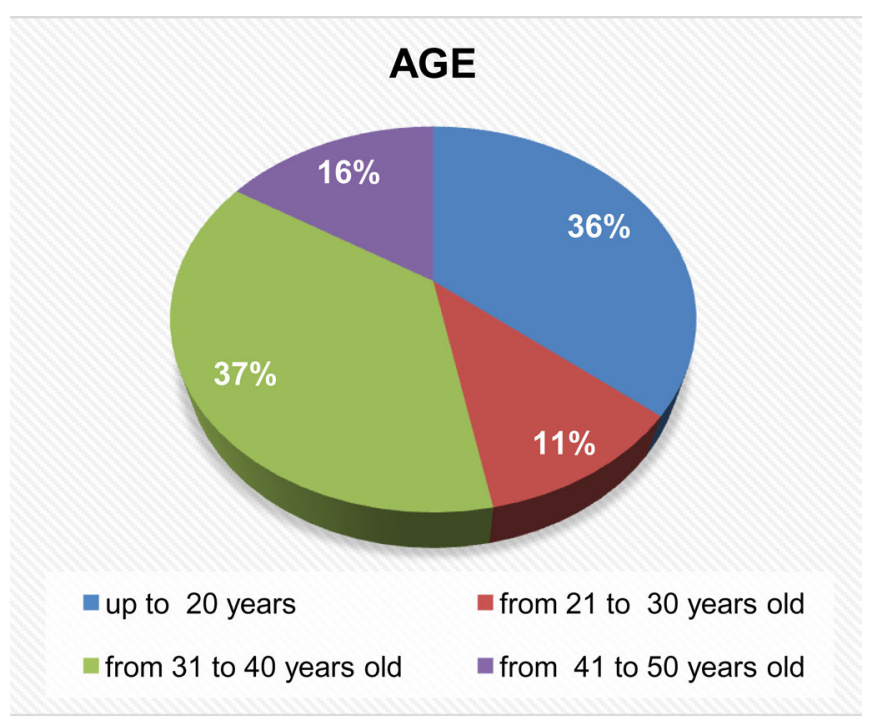

Fig. 1 shows that most interested to study nursing are the candidates at the age of 31 to 40 years $(37 \%)$ and at the age of fewer than 20 years $(36 \%)$. First year students at the age between 41 and 50 years are $16 \%$ and the students at the age between 21 and 30 years are $11 \%$. Re- 
sults show that more than half of the students or $53 \%$ of the first year students in nursing care were at the age between 31 and 50 years in 2017. Obviously, the recommendations for training young specialists and renewal of the staff on the labour market, as promoted by the EU, have not been realized. Medical major are still not enough at- tractive for the students due to the low pay and the quite limited competencies of nurses in Bulgaria.

Students were asked whether in their opinion nursing care would be more attractive for the prospective students if their competencies are extended, fig. 2.

Fig. 2. Opinion of students in nursing care on the relationship between the attractiveness of the nurse and the specific competencies of this profession.

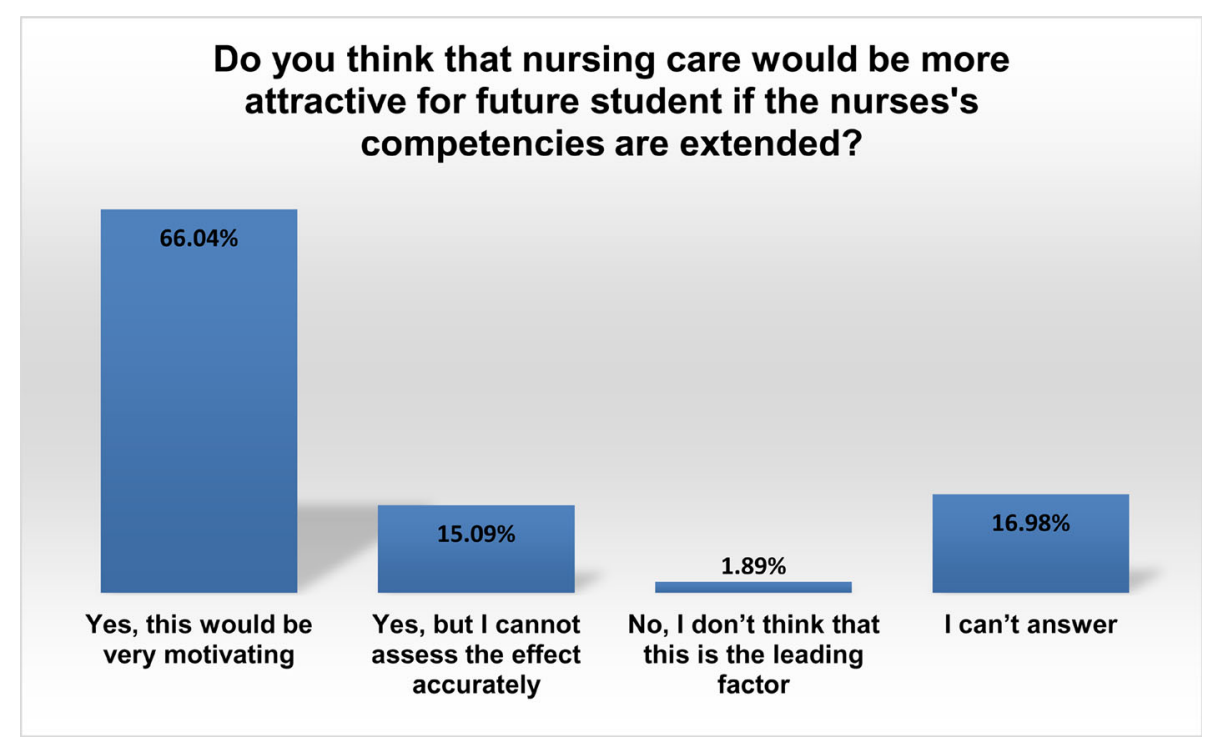

$66.04 \%$ of respondents consider that nursing care would be more attractive for the prospective students if their competencies are extended. Only $1.89 \%$ of the respondents answered that in their opinion the scope of competences of nurses is not the leading factor in selecting the relevant major. $16,98 \%$ of the respondents answered that they are not able to assess what would be the effect and 15,09\% consider that if the competences of nurses are extended, it will make the major more attractive although they are not able to assess the effect accurately.

Examining the methods and opportunities for increasing the interest to nursing care, the respondents were asked whether the inclusion of mass media and Internet advertising for promotion of majors in health care and attracting new staff in the health care system would have a positive effect, fig. 3 .

Fig. 3. Opinion of students in nursing care on the inclusion of mass media and Internet advertising to promote health specialties and attract new staff to the system.

DO YOU THINK THAT IT WOULD BE USEFUL TO INCLUDE

MASS MEDIA AND INTERNET ADVERTISING FOR PROMOTION

OF MAJORS IN HEALTH CARE AND ATTRACTING NEW STAFF IN THE HEALTHCARE SYSTEM?

- Yes, I think that it would be very useful

- Yes, although I don't know what would be the effect

no, I don't think that it is necessary

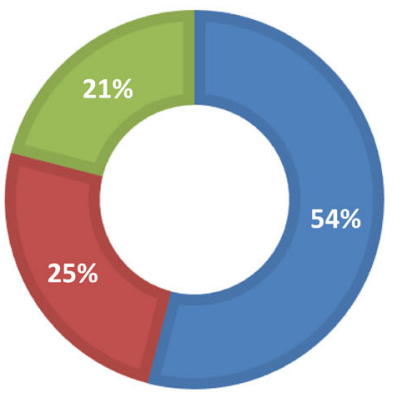


According to more than half of the respondents or $54 \%$ of the respondents, majors in health care would be more attractive for the prospective specialists if mass media and Internet advertising are included for the promotion of the majors in health care. $21 \%$ of the respondents consider that mass media and Internet advertising should be included for the promotion of majors in healthcare although they are not able to assess the specific effect. $25 \%$ of students in nursing care consider that it is not necessary to include mass media and Internet advertising for promotion of majors in health care.

\section{CONCLUSIONS}

There are many challenges on a national and Community level. Health is a main value and healthcare is a part of the national security of any country. Ceaseless migration of health professions and the outflow of candidates in healthcare majors in Bulgaria presents the coun- try with serious challenges. It is necessary to take adequate measures to solve actual problems in health care and to ensure the labour market with health professionals [6]. This requires an active policy for investing in human capital focused on investing in education and professional training of health specialists, investments in the professional qualification of specialists in health care and overcoming the migration processes by creation motivation for the health specialists for a professional career in Bulgaria. The support for health care also supports the economic growth of each country by providing an opportunity for the citizens to remain active and in better health for a longer period of time. The health status of citizens actively affects the participation and the efficiency of the labour market. Investments for the health of the population contribute to limiting future expenses for treatment of preventable diseases and represent investments for assurance effective workforce.

\section{REFERENCES:}

1. Green Book on workers in Health, Brussels, 23.10.2007, COM healthcare in Europe, Brussels, COM (2008) 725 [nternet]

2. Communication from the Commission - Europe 2020 A strategy for smart, sustainable and inclusive growth, COM (2010) 2020 final, 3.3.2010 [Internet]

3. White Paper: Together for
(2007) 630. [Internet]

4. Treaty establishing the European

Community (Consolidated version 2002), OJ C 325, 24.12.2002. [Internet]

5. Council Recommendation of 11 July 2017 on the 2017 National Reform Programme of Bulgaria and deliv- ering a Council opinion on the 2017 Convergence Programme of Bulgaria (2017/C/261/02) [in Bulgarian]

6. Dubois CA, McKee M, Nolte E. Human Resources for Health in Europe (European Observatory on Health Systems and Policies). Open University Press; 1 edition (December 1, 2005), p. 4. [Internet]

Please cite this article as: Gradinarova N, Ivanov E. Problems and perspectives for the labour market in health care Bulgaria as a part of the European Union and the Community policies. J of IMAB. 2018 Oct-Dec;24(4):2201-2204.

DOI: https://doi.org/10.5272/jimab.2018244.2201

Received: 01/06/2018; Published online: 15/10/2018

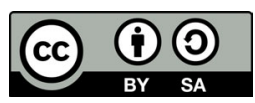

\author{
Address for correspondence: \\ Neli Gradinarova, \\ Department of Medical Ethics and Law, Faculty of Public Health, Medical \\ University - Sofia, \\ 8, Bialo More Str., 1527 Sofia, Bulgaria \\ E-mail: neli.p.gradinarova@gmail.com
}

